\title{
The Dangers of Academic Bubble Economy from a Young Researcher's Perspective
}

In recent years, it is becoming common to apply the metaphor of ,economic bubble" to the description of certain phenomena in the academic field. The metaphor is generally used to refer to the difference between the expectable market value of the degree and the investments needed to receive it (see Deresiewicz 2011, Williams 2011, Wood 2011, Reynolds 2012). The analogy is with the economic phenomenon, in particular, the market value of a particular asset, which does not reflect the intrinsic value of that asset.

The starting point of the current study is the hypothesis that the situation above gives us the opportunity to reconsider the analogy and to make it specific from the viewpoint of a conversion strategy, where the focus is shifted from economic to cultural capital. Accordingly, we will try to present a possible (Bourdieuian) application of the ,bubble" concept, where the postulated sphere of validity is the academic field, in which we will examine how cultural capital is objectified and how objectified cultural capital can be converted into its institutionalised form. The primary focus of this examination will be the presentation of the simulacra of objectivised cultural capital, using different perspectives, touching upon its construction, functioning, and pointing out ways to expose it. We will also deal briefly with a difference in valuation, where the scientific value of objectified cultural capital is disparate with the field value of the institutionalised capital which can be gained through it. Finally, we would also like to address a few pragmatic viewpoints of the creation of cultural capital especially important for a young researcher.

In this study - taking the relevant parts of the Bourdieuian capital theory (1986: 244-248.) as a basis - we will work with three types of cultural capital:

1. Embodied: non-objectified skills and scientific competence,

2. Objectified variants of the above: here, mainly, published texts of scientific value

3. Institutionalised objects which display towards society:

a) skills and scientific competence: competition results and university exams

b) objectified variants of the above: e.g. academic titles, ranks, degrees and memberships

The list above also shows the common process of capital conversion: in order to institutionalise a non-objectified cultural capital, first it needs to be objectified. The assessment of the academic value of objectified cultural capital normally requires a 
subjective and intersubjective evaluative gradation according to the criteria of academic consensus. Here, we will not go into the details of the conditions of scholarship or into the current debates about them, but we will go directly to the area where the conditions of scholarship, or a significant proportion of it, are not displayed by the objectified academic capital, only simulated. The reason for this choice is to be able to separate the type of capital within cultural capital where the intrinsic value is greatly determined by its imitational potential. And it is exactly this imitational potential that makes it possible for the person who possesses it to convert it to institutionalised capital. In the following, we will call this type of capital-applying a popular term in the French semiological trend following Baudrillard (1994)_,,simulacrative cultural capital".

Simulacrative cultural capital has three properties, the appearance of one or more of which can make an object distinguishable from normal cultural capital:

1. A more or less convincing imitation of embodied skills and competence which did not contribute to its creation.

2. The embodied skills and competence do not belong to the agent who possesses their objectified form. ${ }^{1}$

3. The object appears on a scene which imitates the scenes of academic scholarship (e.g. academic books, journals, and other publications), but which do not meet the accepted criteria of those academic scenes. Similarly to the naming of simulacative cultural capital, we will call these simulacrative scenes.

According to their several combinatorial variations, the typology of cultural capital can be drawn as follows:

\begin{tabular}{|l|l|l|l|l|}
\hline \multicolumn{1}{|c|}{ Capital } & \multicolumn{2}{|c|}{ Objectivization } & \multicolumn{2}{c|}{ Appearance } \\
\hline & Identical agents & Different agents & Symbolic Scene & Simulacrative Scene \\
\hline Cultural capital $_{\text {emb }}$ & & & & \\
\hline Simulacrum $_{\text {emb }}$ & & & & \\
\hline
\end{tabular}

In the cells that have been left empty, the binary values of 0 or 1 can appear, with the constraint that in the double columns under "Objectivisation" and „Appearance”, the same value cannot appear in both cells. By examining the row matrices of the variables, we can see that the objectivisation results in a legitimate, academically valuable publication, when the embodied cultural capital and the objectified cultural capital to the creation of which it was used both have the same agent, and the object appears in a symbolic scene.

$$
\text { Cultural capital }_{\mathrm{emb}}=\left[\begin{array}{llll}
1_{11} & 0_{12} & 1_{13} & 0_{14}
\end{array}\right]
$$

1 That is, the text was not written by the person under whose name it gets published. 
Accordingly, we can identify the appearance of simulacrative cultural capital and the development of a bubble in the process of objectivisation, where there are changes at least in two values of the row matrix belonging to embodied cultural capital. Three variants are possible if we observe the constraint mentioned earlier:

$$
\begin{aligned}
& \mathrm{A}=\left[\begin{array}{llll}
0_{11} & 1_{12} & 1_{13} & 0_{14}
\end{array}\right], \\
& \mathrm{B}=\left[\begin{array}{lllll}
1_{11} & 0_{12} & 0_{13} & 1_{14}
\end{array}\right], \\
& \mathrm{C}=\left[\begin{array}{llll}
0_{11} & 1_{12} & 0_{13} & 1_{14}
\end{array}\right] .
\end{aligned}
$$

Variant „C" combines in itself the other two deviations from the accepted way, so it will suffice to examine only variants ,A” and „B” in the following.

For variant „A" the picture can be made more subtle if we also take into consideration the relationship between the creator and the owner. The creator can initiate a relationship which may serve the increase of the creator's financial profit and cultural capital, which is facilitated by the owner's already existing institutional capital and reputation. One of the well-known examples for the increase of profit is medical ghostwriting, where pharmaceutical companies have their employees or agents write articles or summaries in which they make their products appear in a positive light, then get these articles published in leading medical journals under the names of key opinion leader academicians (as an example, see Fugh-Berman 2005: 546-47., Anekwe 2010: 267., Stern-Lemmens 2011). These firms profit from the reputation of these academicians, when, through their inclusion, they influence decision makers and medical practitioners to recommend or subscribe their products (McHenry 2010: 132.), while the pseudo-authors giving their names get a publication record into their $\mathrm{CV}$ without any serious background work. In other cases, the creator initiates the relationship not for financial profit, but for the increase of their own cultural capital. The inclusion of a high-reputation co-author will signi-ficantly raise the chances of a relatively unknown young researcher or a group of them to get published in high-impact journals (Chen \& Huang 2007: 1024.), independently of the fact that the co-author makes no contribution at all to the paper (besides giving their name), or their contribution does not add any additional intellectual value to it (e.g. reviewing, mechanical application of statistics, or adopting new data to an existing method).

A relationship initiated by the later owner also aims at the increase of one's own cultural capital. The creator here is a paid writer, from whom the later owner, personally or through a paper mill, orders the text, which he will publish or submit as a thesis under his own name. In these cases the creator usually gets remuneratedaccording to quality level, length, and execution time-directly or through their agent.

Variant „B" describes cases where the creator and the owner are the same person but the scene of publication does not have the same scientific value as those accepted as scenes of objectified cultural capital. The difference can be attributed to the 
characteristics of simulacrative scenes (examples for which are scamferences, bogus journals or scam journals and various types of vanity publishing). Unlike in symbolic scenes, the criterium of appearing in a simulacrative scene is not academic value but financial compensation (on average, the equivalent of 100 Euro to 500 Euro) of the agent providing the scene, which officially goes under the title „publication fee” or ,registration fee”. However, having the paper published is only a negligible part of the service purchased for this sum because since the beginning of the digital age and with the spread of the internet, digital self-publication would mean a virtually zero-cost alternative to that. The real value to the client is brought about by the simulation of the characteristics of a symbolic scene. The efficiency of this simulation differs from scene to scene and from subcategory to subcategory but it is sufficiently enough to make a reference in a list of publications formally conform to references to texts which appeared on symbolic scenes. Besides effective simulation, these scenes can provide almost all the formal attributes of a symbolic scene: for example, a scam journal may have an extended international editorial board, an editorial advisory board, a system of pre-publication peer review, a professional website and-as it can be seen from the case of the six fake journal published by Elsevier (Hutson 2009: 598., Collier 2009: 254-255.)—even a professional publishing background and may be included in scientific databases, as well.

Turning to cases where the simulation is not of authorship but of the various types of embodied cultural capital, we can divide these-according how they are utilised-into subversive, preventive, and corrective applications.

Subversive applications are the techniques which refer to such intellectual work or competence of the author which he or she did not do or did not possess at the time the object was created. Examples for these are making up research data (,dry-labbing”), citation plagiarism, using references solely for bibliography padding, and various other types of scientific misconduct.

The preventive and corrective applications of the simulacra of embodied cultural capital on the other hand are connected not to the object but to the scenes of its appearance.

The primary objective of preventive applications (Simulacrum $_{\mathrm{emb}}=\left[1_{11}\right.$ $\left.\begin{array}{llll}0_{12} & 0_{13} & 1_{14}\end{array}\right]$ and $\left.\left[\begin{array}{llll}0_{11} & 1_{12} & 0_{13} & 1_{14}\end{array}\right]\right)$ is the disclosure of simulacrative scenes. As we have already mentioned at the discussion of these scenes, they mostly function as business enterprises, therefore they are interested in receiving a publication or registration fee independently of the academic value of the object. For the detection of this practice, some participants of academic life, typically of the younger generation, volunteer to compose or to compile with the help of text generators (e.g. The Postmodernism Generator, SCIgen) some texts and they send these academically worthless products to scenes deemed as suspicious. If these texts are accepted for publication and a notice 
for publication or registration fee is received, they take it as a proof for the lack of academic control and they collect and publish the data of the scenes on internet sites, blogs, and in newsletters specialised in this subject.

Corrective applications of simulacrative embodied cultural capital $\left(\right.$ Simulacrum $\left._{\mathrm{emb}}=\left[\begin{array}{lllll}1_{11} & 0_{12} & 1_{13} & 0_{14}\end{array}\right]\right)$ targets not simulacrative but symbolic scenes and their objective is not mere deterrence but to draw attention to the necessity of discussion about an anomaly of the academic field. One of the best-known of these simulacra was prepared by Alan Sokal, whose study was published in Social Text in 1996, which in his words ,was liberally salted with nonsense (1996)", with which he intended to prove that in scientific publication conformity to various ideological preconceptions and positions of power plays a much more important role than scientific value.

It can be seen from the cases examined above that the development of a bubble during the objectivisation of embodied cultural capital is greatly supported by a micro-economy leaning over the academic field and often even merging into it, which is characterised as a market where cultural capital and scenes of public appearance are sold and bought. The effects of this economy may be felt in the processes of institutionalisation if the simulation is successful enough. A direct influence can also appear, for example, in the form of academic bribery. Nevertheless, a conversion unproportional to value can occur during objectivisation and institutionalisation independently of the economy above. Various cases of granting academic and university statuses as a result of nepotism (Allesina 2011) and (not necessarily political) pressure prove that not always cultural but mainly social or political capital gets institutionalised. The role of symbolic violence in the process of institutionalisation was described by Bourdieu in the 1980's in his Homo Academicus (1984). He points out in his examination of the role of symbolic violence that objectified cultural capital does not get institutionalised for its academic value but according to meeting the commitments of the decision makers. Differences in value preferences and priorities in the academic work can also lead to the development of an institutionalisation bubble for agents of a hierarchy entering or giving admittance to the institutional field.

As a summary of phenomena characterising academic bubble economy, one can raise the question: what significance does it have for researchers, especially for young researchers at the beginning of their careers? The question cannot be left unanswered because getting academic publications and gaining membership to academic institutions may force the young researcher to give up the status of a freefloating intellectual and to make uneasy compromises. Nowadays, the tendency is relatively widely known and discussed that the rejection of a paper may be significantly influenced by an epistemological conflict of interests, which arises when a reviewer evaluates a paper from an epistemological point of view inconsistent with the author's (Shimp 2004: 113-114., Mallard-Lamont-Guetzkow 2009, Souder 2011: 62.). It is also known that in order to gain institutional promotion one may be 
advised to avoid ,too much" research or even to abandon research on certain topics (Knight 2010: 85-86). The epistemic gatekeeper role of peer reviewers and institutional referees creates a situation where the effectiveness of the conversion between different forms of cultural capital, independently of their scientific value, is greatly reduced, not excluding its reduction to zero. All this points to a direction where both an agent capable of a continuous paradigmatic conformity to the current situation and one committed to an epistemic paradigm which has a long history in academic scholarship have a definite advantage over a disinterested intellectual.

Naturally, it would show considerable naivety if one believed that the majority of trade on simulacrative scenes is made up by those researchers who are looking for alternative ways of getting published specifically because of the gatekeepers. The necessity to produce the ,entrance fee" to the academic field, and, following the entrance, the publication pressure connected to successful operation and development create such an environment which reduces the majority of rational capital development strategies to the optimisation of the value of time/quantity and time/scientometric ratios. By the inclusion of simulacrative cultural capital, these rational capital building techniques get ,enriched” by a speculative element where the researcher makes a bet on the effectiveness of the simulation: they hope that the risk of detection and the consequences of such a disclosure are lower than the profit they can gain from the imitation of cultural capital. Although this practice can and should be criticised on moral grounds, its pragmatic significance goes beyond the ethical dimension. The conversion of simulacrative cultural capital into ,real” cultural capital results in the strengthening of a hyperreal academic field, which floats detached from real science but, nonetheless, has the ability to affect real science. In my opinion, the main decision researchers have to make here is either to commit themselves to the development of a real scientific identity and to become members of the scientific community, or to act as mediators between the real and the hyperreal.

\section{Bibliography}

Allesina, Stefano (2011): Measuring Nepotism through Shared Last Names: The Case of Italian Academia. PLoS ONE 6 (8). Internet: http://dx.doi.org/10. 1371/journal.pone.0021160, downloaded: 07/04/2012.

Anekwe, Tobenna D. (2010): Profits and Plagiarism: The Case of Medical Ghostwriting. Bioethics 24 (6), 267-272.

Baudrillard, Jean (1984 [1981]): Simulacra and Simulations. Ann Arbor, The University of Michigan Press.

Bourdieu, Pierre (1984): Homo Academicus. Paris, Les Éditions de Minuit.

Bourdieu, Pierre (1986): The forms of capital. In J. Richardson (ed.): Handbook of Theory and Research for the Sociology of Education. New York, Greenwood, 241-258.

Chen, CARL R.-HuAng, Ying (2007): Author Affiliation Index, finance journal ranking, and the pattern of authorship. Journal of Corporate Finance 13 (5), 1008-1026. 
Collier, Roger (2009): Medical literature, made to order. CMAJ: Canadian Medical Association Journal 181 (5), 254-256.

Deresiewicz, William (2011): Faulty Towers. Nation 292 (21), 27-34.

Fugh-Berman, Adriane (2005): The Corporate Coauthor. JGIM: Journal of General Internal Medicine 20 (6), 546-548.

Hutson, Stu (2009): Publication of fake journals raises ethical questions. Nature Medicine 15 (6), 598-598.

Knight, Wanda B. (2010): Sink or Swim: Navigating the Perilous Waters of Promotion and Tenure-What's Diversity Got to Do with It? Studies in Art Education: A Journal of Issues and Research in Art Education 52 (1), 84-87.

Mallard, Grégoire-Michèle Lamont-Joshua GuetzKow (2009): Fairness as appropriateness: Negotiating epistemological differences in peer review. Science, Technology and Human Values 34 (5), 573-606. Internet: http:// dx.doi.org/10.1177/0162243908329381, downloaded: 07/04/2012.

MCHenry, LeEmon (2010): Of Sophists and Spin-Doctors: Industry-Sponsored Ghostwriting and the Crisis of Academic Medicine. Mens Sana Monographs (8), 129-145.

Reynolds, Glenn Harlan (2012): The College Bubble. Popular Mechanics 189 (1), 43-45.

Shimp, Charles P. (2004): Scientific peer review: a case study from local and global analyses, Journal of the Experimental Analysis of Behavior, 82 (1), 103-116.

SoKal, Alan (1996): A Physicist Experiments with Cultural Studies. Internet: http:// linguafranca.mirror.theinfo.org/9605/sokal.html, downloaded: 07/04/2012.

SOUDER, LAWRENCE (2011): The ethics of scholarly peer review: a review of the literature. Learned Publishing 24 (1), 55-72. Internet: http://dx.doi.org/10. 1087/20110109, downloaded: 07/04/2012.

Stern, Simon-Lemmens, Trudo (2011): Legal Remedies for Medical Ghost-writing: Imposing Fraud Liability on Guest Authors of Ghostwritten Articles. PLoS Med 8 (8). Internet: http://dx.doi.org/10.1371/journal.pmed.1001070, downloaded: 07/04/2012.

WiLliAMS, GARETH (2011): Will higher education will be the next bubble to burst? Internet: http://www.educationarena.com/pdf/sample/sample-essaywilliams.pdf, downloaded: 07/04/2012.

Wood, Peter (2011): The higher education bubble. Society 48 (3), 208-212. 